$\mathrm{B}$ Декларации Тысячелетия ООН, принятой 193 государствами-членами ООН и 23 международными организациями в сентябре 2000 г. названо восемь Целей развития тысячелетия. На наш взгляд, не все Цели смогут быть достигнуты к 2015 г., к сожалению это и три самые важные, являющиеся посланием в будущие поколения - сокращение детской смертности, улучшение охраны материнского здоровья, борьба с ВИЧ/СПИДом, малярией и прочими заболеваниями ${ }^{1}$.

Одним из существенных тормозов законности, а значит и прогресса в сфере здравоохранения является коррупция. Ни одна страна в мире не свободна от коррупции, в том числе в области здравоохранения, ее реальные размеры, как в мировых масштабах, так и в масштабах отдельной страны трудно подсчитать, учитывая, что оборот всемирной индустрии медицинских услуг превышает 3 млрд. долларов США.

В Докладе Трансперенси Интереншнл о Положении дел с коррупцией в мире за 2006 г. было подчеркнуто, что коррупция в сфере здравоохранения лишает наиболее нуждающихся доступа к базовым медицинским услугам и способствует стремительному распространению лекарственно-резистентных форм смертельных заболеваний ${ }^{2}$.

Система здравоохранения особенно уязвима к коррупции из-за оборота в ней значительного количества юридических и физических лиц: плательщиков, поставщиков и пациентов. В России медицинские услуги оказываются как частными, так и муниципальными, государственными, ведомственными медицинскими учреждениями.

Следует учитывать, что в РФ за четыре последних года расходы федерального бюджета на здравоохранение увеличились в два раза: с 202,8 миллиардов рублей до 413 миллиардов рублей

При этом, согласно ст. 9 Федерального закона от 30 ноября 2011 г. № 371-Ф3 «О федеральном бюджете на 2012 г. и на плановый период 2013 и 2014 гг.» в по-

\footnotetext{
1 http://www.un.org/russian/millenniumgoals/childhealth.shtml

2 http://www.transparency.org.ru/

3 См.: Краснопольская И. В России увеличились расходы на здравоохранение // Российская газета. - 2012. - 18 марта.
}

рядке, установленном Правительством РФ, осуществляется использование бюджетных ассигнований на:

1) финансовое обеспечение закупок диагностических средств и антивирусных препаратов для профилактики, выявления, мониторинга лечения и лечения лиц, инфицированных вирусами иммунодефицита человека и гепатитов В и С;

2) закупки оборудования и расходных материалов для неонатального и аудиологического скрининга в учреждениях систем здравоохранения;

3) закупки лекарственных препаратов, предназначенных для лечения больных злокачественными новообразованиями лимфоидной, кроветворной и родственных им тканей по перечню заболеваний, утверждаемому Правительством РФ, гемофилией, муковисцидозом, гипофизарным нанизмом, болезнью Гоше, рассеянным склерозом, а также после трансплантации органов и (или) тканей, по перечню лекарственных препаратов, утверждаемому Правительством РФ, с учетом данных Федерального регистра больных гемофилией, муковисцидозом, гипофизарным нанизмом, болезнью Гоше, злокачественными новообразованиями лимфоидной, кроветворной и родственных им тканей, рассеянным склерозом, а также после трансплантации органов и (или) тканей, содержащего сведения о гражданах, перечисленных в ст. 6.1 Федерального закона от 17 июля 1999 г. № 178-ФЗ «О государственной социальной помощи», и виде заболевания, ведение которого осуществляется федеральным органом исполнительной власти, осуществляющим функции по выработке государственной политики и нормативноправовому регулированию в сфере здравоохранения, социального развития, труда и защиты прав потребителей, в установленном им порядке;

4) финансовое обеспечение денежных выплат медицинскому персоналу фельдшерско-акушерских пунктов, врачам, фельдшерам и медицинским сестрам станций (отделений) скорой медицинской помощи федеральных государственных учреждений здравоохранения, подведомственных Федеральному медико-биологическому агентству;

5) финансовое обеспечение оказания дополнительной медицинской помощи врачами-терапевтами 
участковыми, врачами-педиатрами участковыми, врачами общей практики (семейными врачами), медицинскими сестрами участковыми врачей-терапевтов участковых, врачей-педиатров участковых, медицинскими сестрами врачей общей практики (семейных врачей) учреждений здравоохранения, находящихся в ведении Российской академии наук и Сибирского отделения Российской академии наук, при условии размещения в этих медицинских учреждениях муниципального заказа на оказание первичной медико-санитарной помощи, а также федеральных государственных учреждений здравоохранения, находящихся в ведении Федерального медико-биологического агентства;

6) финансовое обеспечение оказания высокотехнологичной медицинской помощи гражданам РФ;

7) оплату расходов, связанных с лечением граждан РФ за пределами территории РФ;

8) реализацию мероприятий, направленных на совершенствование организации медицинской помощи пострадавшим при дорожно-транспортных происшествиях;

9) реализацию мероприятий, направленных на совершенствование медицинской помощи больным с сосудистыми заболеваниями;

10) финансовое обеспечение мероприятий по развитию службы крови;

11) финансовое обеспечение проведения дополнительной диспансеризации работающих граждан федеральными государственными учреждениями здравоохранения, находящимися в ведении Федерального медико-биологического агентства;

12) финансовое обеспечение мероприятий, направленных на совершенствование медицинской помощи больным с онкологическими заболеваниями;

13) финансовое обеспечение мероприятий, направленных на формирование здорового образа жизни у населения РФ, включая сокращение потребления алкоголя и табака;

14) финансовое обеспечение создания информационной системы в здравоохранении;

15) финансовое обеспечение мероприятий, направленных на обследование населения с целью выявления туберкулеза, лечения больных туберкулезом, профилактических мероприятий;

16) финансовое обеспечение мероприятий, направленных на проведение пренатальной (дородовой) диагностики;

17) финансовое обеспечение мероприятий, направленных на дополнительную подготовку врачей;

18) реализацию комплекса мер по выхаживанию новорожденных с низкой и экстремально низкой массой тела;

19) финансовое обеспечение создания обучающих симуляционных центров;
20) финансовое обеспечение мероприятий, направленных на развитие неонатальной хирургии;

21) закупку медицинских иммунобиологических препаратов в рамках Национального календаря профилактических прививок ${ }^{4}$.

Практически без должного контроля указанные функции осуществляются должностными лицами, которые зачастую проводят тендеры на поставку, приобретение оборудования и лекарств, проведение мероприятий, имея свой материальный интерес. Также распространенным фактом является то, что медицинские учреждения в своей структуре формируют коммерческие структуры, в результате чего пациенты вынуждены пользоваться услугами платно. Сотрудники медицинских учреждений, в том числе должностные лица вымогают деньги за бесплатные услуги.

Регулирующие органы, плательщики, поставщики медицинских услуг и их потребители сталкиваются с целым комплексом стимулов коррупционного поведения.

Исследователи выделяют следующие формы коррупции в сфере здравоохранения:

1) растрата и расхищение средств, выделенных на здравоохранение, или доходов, полученных за счет платежей со стороны потребителей. Эти явления могут происходить как на государственном уровне и уровне органов местного самоуправления, так и непосредственно в медицинских организациях и учреждениях, получающих такие средства. Лекарства, а также другие ресурсы и оборудование медицинского назначения могут расхищаться для личного пользования, использования в частной практике или в целях дальнейшей перепродажи;

2) коррупция в сфере государственных закупок. Вовлеченность в различные сговоры, взяточничество и получение «откатов» в сфере государственных закупок приводит к переплатам за получаемые товары и услуги или к невозможности обеспечения качества, обусловленного контрактами для таких товаров и услуг. Кроме того, расходы больниц могут включать значительные затраты на капитальное строительство и приобретение дорогостоящего оборудования;

3) коррупция в платежных системах. Здесь коррупционные действия могут включать бесплатное обслуживание, подделку страховых документов или использование средств медицинских учреждений в интересах тех или иных привилегированных пациентов; выставление незаконных счетов страховым компаниям, государственным органам или пациентам в отношении не входящих в соответствующие перечни или вовсе не оказанных услуг в целях максимизации доходов; подделка счетов, квитанций, расходных документов или учет фиктивных пациентов;

4 СЗ РФ. - 2011. - № 49 (ч. 1). - Ст. 7049. 
4) развитие собственного бизнеса за счет создания финансовых стимулов или выплаты «откатов» врачам за направление пациентов в ту или иную организацию; неправомерное направление врачами пациентов государственных медицинских учреждений на обслуживание в собственные частные структуры; проведение неоправданного медицинского вмешательства в целях увеличения собственных доходов;

5) коррупция в системе поставок лекарственных препаратов. Препараты могут расхищаться на различных уровнях системы распределения. Государственные чиновники могут требовать «вознаграждение» за выдачу разрешений на продажу продукции или работу тех или иных структур, за проведение таможенной очистки или установление выгодных цен. Нарушение кодексов поведения на рынке приводит к тому, что врачи вынуждены отдавать предпочтение определенным лекарствам при выписке рецептов. У поставщиков могут вымогаться различные уступки при условии выписки рецептов на их продукцию. Еще одной возможной формой коррупционных действий является выдача разрешений на торговлю поддельными или некачественными лекарственными препаратами;

6) коррупция в учреждениях, предоставляющих медицинские услуги, может принимать и другие формы: вымогательство или согласие на получение незаконного вознаграждения за услуги, официально оказываемые бесплатно; взимание платы за особые привилегии или медицинские услуги; вымогательство или согласие на получение взяток за вмешательство в практику найма, лицензирования, аккредитации или сертификации тех или иных структур 5 .

Как мы видим, практически все из вышеназванных правонарушений могут выполняться юридическими лицами. Однако в России до настоящего времени нет их уголовной ответственности за столь серьезные общественно опасные деяния, в том числе в сфере здравоохранения. В этой связи, безусловно, значимым является проект Федерального закона «О внесении изменений в некоторые законодательные акты Российской Федерации в связи с введением института уголовно-правового воздействия в отношении юридических лиц» ${ }^{6}$.

\footnotetext{
5 См.: Аналитический вестник Аналитического управления Аппарата Совета Федерации // http:/www.council.gov.ru/ inf_ps/parlisurvey/2008/11/81/item3815.html.

6 Проект Федерального Закона «О внесении изменений в некоторые законодательные акты РФ в связи с введением института уголовно-правового воздействия в отношении юридических лиц»// Официальный сайт Следственного комитета РФ [Электрон. ресурс] URL: http://www.sledcom.ru/ discussions/?SID=1273 (дата обращения: 15.06.2011) и Проект Федерального закона № 47538-6 «О внесении изменений в ча-
}

Так, ст. 10 Конвенции ООН против транснациональной организованной преступности, а также дополняющие ее Протоколы обязывают ввести уголовную ответственность юридических лиц за причастность к организации преступного сообщества, отмыванию имущества и доходов, полученных преступным путем, к коррупции, преступлениям против правосудия, организации незаконной миграции и к торговле людьми. Ст. 26 Конвенции ООН против коррупции устанавливает обязанность ввести уголовную ответственность юридических лиц за причастность к преступлениям коррупционной направленности, относя к этой категории в том числе подкуп должностных лиц иностранного государства и корпоративную коррупцию в коммерческих организациях. И, наконец, ст. 18 Конвенции об уголовной ответственности за коррупцию предусматривает, что юридическое лицо должно нести уголовную ответственность в том числе и за ненадлежащую организацию внутреннего корпоративного контроля за деятельностью лиц, занимающих должности в органах его управления, что повлекло возможность совершения преступления коррупционной направленности.

В мировой практике правового регулирования института уголовной ответственности юридических лиц сложилось три базовые модели. Первая из них основывается на традиционной конструкции, при которой корпорация наряду с физическим лицом рассматривается в качестве самостоятельного субъекта преступления. Она характерна для стран общего права - Англии, Шотландии, Ирландии, США, Канады, Австралии и др. А также для стран, принадлежащих к романо-германской семье права, - Австрии, Бельгии, Голландии, Люксембурга, Португалии, Франции, Финляндии и др. Кроме того, она инкорпорирована в правовые системы бывших республик СССР - Грузии, Литвы, Молдовы, Эстонии. Мировые стандарты противодействия преступности юридических лиц диктуют необходимость внедрения института ответственности юридических лиц за причастность к преступлению именно в уголовное законодательство. В частности, Российская Федерация присоединилась к Конвенции ООН против транснациональной организованной преступности, Конвенции ООН против коррупции и к Конвенции об уголовной ответственности за коррупцию, которые предусматривают обязанность государств-участников ввести уголовную ответственность юридических лиц за причастность к определенным видам преступлений.

В странах Европы специалисты и руководители здравоохранения озабочены коррупцией, приводящи-

сти первую, вторую, третью и четвертую Гражданского кодекса РФ, а также в отдельные законодательные акты РФ» (ред., принятая ГД ФС РФ в I чтении 27.04.2012) // Документ опубликован не был. Справочная система «Консультант плюс». 
ми к разворовыванию бюджетных средств и убыткам компаний медицинского страхования7. Например, израильская фармацевтическая компания Теvа получила запрос в рамках расследования соблюдения фармацевтическими компаниями закона о коррупции за рубежом от Комиссии по биржам и ценным бумагам США (SEC) и Минюста США о предоставлении документации, связанной с деятельностью компании в Латинской Америке. В 2011 г. Johnson\&Johnson согласился заплатить 70 млн долл. США в рамках урегулирования обвинений в адрес ряда подразделений компании в подкупе врачей в Европе.

Считаем возможным изучить опыт зарубежных стран в противодействии коррупции в сфере здравоохранения, так можно воспользоваться опытом Таиланда, в котором еще в 2004 г. для борьбы с коррупцией в сфере оборота лекарственных средств предприняли следующие меры. Во-первых, для снижения расходов на закупки качественных лекарств увеличили число больниц, использующих наилучшие практические методики закупок лекарственных средств, создали объединенную схему закупок больницами лекарственных средств в соответствии с согласованным перечнем лекарственных средств и их поставщиков.

Во-вторых, пересмотрели национальные фармацевтические законы и правила, создали национальную базу данных о надлежащем управлении в области лекарственных средств, содержащую публикации и статьи о коррупции, неэтичных практических методиках и случаях коррупции.

В-третьих, расширили доступ к информации: создали информационные бюллетени, сообщения для общественности и СМИ, брошюры и веб-сайты; в свободный доступ разместили протоколы национальных совещаний по вопросам лекарственных средств, предмет «надлежащее управление» включили в учебную программу 15 фармацевтических факультетов ${ }^{8}$.

В Молдове были приняты Закон о правах и ответственности пациента и Закон о выполнении обязанностей врача, которые имели целью предупреждение коррупции и улучшение качества медицинских услуг, а также внутренний План по реализации Национальной стратегии о предупреждении и борьбе с коррупцией в области здравоохранения, разработка которой связана с внедрением раздела «Предупреждение и борьба с коррупцией в области здравоохранения» и програм-

\footnotetext{
7 См.: Лазаренко А. Коррупция: Европа страдает тоже // Медицинская газета. - 2012. - 7 сентября.

8 Целевое исследование в Таиланде: надлежащее управление и предотвращение коррупции//http:/www.who.int/ features/2010/medicines_thailand/ru/print.html.2010 г.
}

мы действий по внедрению Предварительного Плана Республики Молдова в этой сфере 9

Одним из возможно эффективных способов противодействия коррупции, в том числе юридических лиц в сфере здравоохранения считаем введение различных государственных реестров государственных и иных медицинских услуг. Учитывая, что в настоящее время в Российской Федерации сформировались необходимые условия для перехода к информационному обществу, и, несомненно, одним из таких условий является развитие системы нормативного правового регулирования отношений в информационной сфере. Определяемая Государственной программой РФ «Информационное общество (2011-2020 гг.)», задача перевода в электронный вид государственной учетной деятельности должна быть обеспечена необходимым правовым регулированием.

Перевод в электронный вид государственной учетной деятельности предусматривается Государственной программой РФ «Информационное общество (20112020 гг.)» ${ }^{10}$.

Мы разделяем мнение Л.В. Филатовой, что государственная учетная деятельность - деятельность органов государственной власти в рамках нормативно установленных полномочий по сбору, хранению, обработке и предоставлению гражданам, организациям, органам власти и местного самоуправления сведений об объектах, субъектах, юридически значимых событиях и действиях. Например, сведения о нормативных правовых актах, официальном опубликовании, практике применения, о результатах правовой, антикоррупционной экспертизы и т.п. ${ }^{11}$.

В системе здравоохранения ведутся различные реестры, назовем некоторые:

1) реестр предельных отпускных цен производителей на лекарственные препараты, включенные в перечень жизненно необходимых и важнейших лекарственных препаратов (Постановление Правительства РФ от 29 октября 2010 г. № 865 «О государственном регулировании цен на лекарственные препараты, включенные в перечень жизненно необходимых и важнейших лекарственных препаратов» (вместе с «Правилами государственной регистрации предельных отпускных цен производителей на лекарственные препараты, вклю-

\footnotetext{
9 Коррупцию можно победить усилиями всего общества. Интервью с замминистра здравоохранения М. Буга http:// www.nm.md/daily/article/2008/01/15/0303.html.

10 Распоряжение Правительства РФ от 20 октября 2010 г. № 1815-р в ред. от 02.12.2011 № 2161 / КонсультантПлюс.

11 См.: Филатова Л.В. Теоретико-правовые вопросы систематизации информационного законодательства в процессах государственной учетной деятельности // Государственная власть и местное самоуправление. - 2012. - № 3. - С. 43.
} 
ченные в перечень жизненно необходимых и важнейших лекарственных препаратов», «Правилами ведения государственного реестра предельных отпускных цен производителей на лекарственные препараты, включенные в перечень жизненно необходимых и важнейших лекарственных препаратов», «Правилами установления предельных размеров оптовых и предельных размеров розничных надбавок к фактическим отпускным ценам производителей на лекарственные препараты, включенные в перечень жизненно необходимых и важнейших лекарственных препаратов, в субъектах РФ») ${ }^{12}$;

2) реестр лекарственных средств для медицинского применения (Приказ Минздравсоцразвития РФ от 26 августа 2010 г. № 746н «Об утверждении порядка ведения государственного реестра лекарственных средств для медицинского применения») $)^{13}$;

3) реестр разрешений на ввоз конкретной партии предназначенных для медицинского применения зарегистрированных и (или) незарегистрированных лекарственных средств, выданных Министерством здравоохранения и социального развития РФ, и решений об отказе в выдаче разрешения на ввоз конкретной партии предназначенных для медицинского применения зарегистрированных и (или) незарегистрированных лекарственных средств (Приказ Минздравсоцразвития РФ от 2 ноября 2010 г. № 952н «Об утверждении формы реестра разрешений на ввоз конкретной партии предназначенных для медицинского применения зарегистрированных и (или) незарегистрированных лекарственных средств, выданных Министерством здравоохранения и социального развития РФ, и решений об отказе в выдаче разрешения на ввоз конкретной партии предназначенных для медицинского применения зарегистрированных и (или) незарегистрированных лекарственных средств» ${ }^{14}$;

4) реестр выданных разрешений (решений об отказе в выдаче разрешений) на ввоз на территорию РФ и вывоз за пределы территории РФ биологических материалов (образцы биологических жидкостей, тканей, секретов и продуктов жизнедеятельности человека, физиологических и патологических выделений, мазков, соскобов, смывов, микроорганизмов, биопсийный материал), полученных при проведении клинического исследования лекарственного препарата для медицинского применения (Приказ Минздравсоцразвития РФ от 2 ноября 2010 г. № 951н «Об утверждении формы реестра выданных разрешений (решений об отказе в выдаче разрешений) на ввоз на территорию РФ и вывоз за пределы территории РФ биологических материалов (образцы биологических

12 С РФ. - 2010. - № 45. - Ст. 5851.

13 Российская газета. - 2010. - 10 сентября.

14 Российская газета. $-2010 .-8$ декабря. жидкостей, тканей, секретов и продуктов жизнедеятельности человека, физиологических и патологических выделений, мазков, соскобов, смывов, микроорганизмов, биопсийный материал), полученных при проведении клинического исследования лекарственного препарата для медицинского применения») ${ }^{15}$;

5) реестр выданных разрешений на проведение клинических исследований лекарственных препаратов для медицинского применения (Приказ Минздравсоцразвития РФ от 26 августа 2010 г. № 754н «Об утверждении порядка ведения, опубликования и размещения на официальном сайте в сети «Интернет» реестра выданных разрешений на проведение клинических исследований лекарственных препаратов для медицинского применения») $)^{16}$;

6) реестр выданных разрешений на проведение клинических исследований лекарственных препаратов для медицинского применения (Приказ Минздравсоцразвития РФ от 26 августа 2010 г. № 751н «Об утверждении правил ведения реестра исследователей, проводящих (проводивших) клинические исследования лекарственных препаратов для медицинского применения, и порядок его размещения на официальном сайте Министерства в сети «Интернет») ${ }^{17}$;

7) реестр и информационной системе учета продукции, веществ, препаратов, прошедших государственную регистрацию (Приказ Роспотребнадзора от 9 сентября 2004 г. № 13 «О Государственном реестре и информационной системе учета продукции, веществ, препаратов, прошедших государственную регистрацию» (вместе с «Положением о Государственном реестре и информационной системе учета продукции, веществ, препаратов (кроме лекарственных средств), прошедших государственную регистрацию в Федеральной службе по надзору в сфере защиты прав потребителей и благополучия человека») ${ }^{18}$;

8) «Государственный реестр лекарственных средств» ${ }^{19}$ и др.

Ранее предпринимались попытки создать реестр медицинских услуг в сфере здравоохранения, например в июне 2011 г. Однако нормативно он до настоящего времени не принят. Считаем, что государственная учетная деятельность в сфере здравоохранения будет способствовать противодействию коррупции, в том числе юридических лиц.

\footnotetext{
15 Российская газета. - 2010. - 24 декабря.

16 Российская газета. - 2010. - 10 сентября.

17 Российская газета. $-2010 .-10$ сентября.

18 Российская газета. - 2004. - 23 сентября.

19 Текст документа на сайте http:/grls.rosminzdrav.ru/grls. aspx, по состоянию на 04.10.2012.
} 


\section{Библиографический список:}

1. Антонова Е.Ю. Уголовная ответственность юридических лиц и ее соотношение с иными видами юридической ответственности // Уголовное право: стратегия развития в XXI веке. - М., 2006.

2. Березницкий А.Г. Административная ответственность юридических лиц: Автореф. дис. ... канд. юрид. наук. M., 2003.

3. Волженкин Б.В. Уголовная ответственность юридических лиц. - СПб., 1998.

4. Иванов Л. Принцип вины и публичная ответственность юридического лица (к вопросу об уголовной ответственности юридических лиц) // Уголовное право. — 2009. — № 1 .

5. Колесниченко Ю.Ю. Административная ответственность юридических лиц: Автореф. дис. ... канд. юрид. наук. - М., 2000.

6. Малафеева Ю.А. Административная ответственность юридических лиц по новому КоАП РФ: соблюдение принципа вины при привлечении к ответственности // Проблемы обеспечения правоохранительными органами прав и свобод человека и гражданина в современной России. - СПб., 2006, Ч. 2.

\section{References (transliteration):}

1. Antonova E.Yu. Ugolovnaya otvetstvennost' yuridicheskikh lits i ee sootnoshenie s inymi vidami yuridicheskoy otvetstvennosti // Ugolovnoe pravo: strategiya razvitiya v XXI veke. - M., 2006.

2. Bereznitskiy A.G. Administrativnaya otvetstvennost' yuridicheskikh lits: Avtoref. dis. ... kand. yurid. nauk. — M., 2003.

3. Volzhenkin B.V. Ugolovnaya otvetstvennost' yuridicheskikh lits. — SPb., 1998.

4. Ivanov L. Printsip viny i publichnaya otvetstvennost' yuridicheskogo litsa (k voprosu ob ugolovnoy otvetstvennosti yuridicheskikh lits) // Ugolovnoe pravo. — 2009. — № 1 .

5. Kolesnichenko Yu.Yu. Administrativnaya otvetstvennost' yuridicheskikh lits: Avtoref. dis. ... kand. yurid. nauk. M., 2000.

6. Malafeeva Yu.A. Administrativnaya otvetstvennost' yuridicheskikh lits po novomu KoAP RF: soblyudenie printsipa viny pri privlechenii $\mathrm{k}$ otvetstvennosti // Problemy obespecheniya pravookhranitel'nymi organami prav i svobod cheloveka i grazhdanina v sovremennoy Rossii. - SPb., 2006, Ch. 2. 